\title{
Correction to: Transient analysis of piecewise homogeneous Markov fluid models
}

\author{
Salah Al-Deen Almousa ${ }^{1}$ - Gábor Horváth ${ }^{1} \cdot$ Miklós Telek $^{1,2}$ (D)
}

(c) Springer Science+Business Media, LLC, part of Springer Nature 2021

\section{Correction to: Annals of Operations Research https://doi.org/10.1007/s10479-020-03831-1}

Affiliation for author Miklos Telek was missing in the original publication and should be read as:

Department of Networked Systems and Services, Budapest University of Technology and Economics, Budapest, Hungary and MTA-BME Information Systems Reseach Group, Hungary.

Along with

Department of Networked Systems and Services, Budapest University of Technology and Economics, Budapest, Hungary.

Original article has been updated.

Publisher's Note Springer Nature remains neutral with regard to jurisdictional claims in published maps and institutional affiliations.

The original article can be found online at https://doi.org/10.1007/s10479-020-03831-1.

Miklós Telek

telek@hit.bme.hu

Salah Al-Deen Almousa

almousa@hit.bme.hu

Gábor Horváth

ghorvath@hit.bme.hu

1 Department of Networked Systems and Services, Budapest University of Technology and Economics, Budapest, Hungary

2 MTA-BME Information Systems Reseach Group, Budapest, Hungary 